\title{
Epidemiological Study on Acute Viral Hepatitis Outbreak in Chattogram Cantonment Area
}

\author{
Chowdhury $\mathrm{MI}^{1}$, Hossain $\mathrm{MD}^{2}$, Rahman $\mathrm{SMM}^{3}$, Miah MAI
}

DOI: https://doi.org/10.3329/jafmc.v16i1.53837

\begin{abstract}
Introduction: Acute viral hepatitis (AVH) incidence had suddenly increased at Artillery Centre and School (AC\&S) at Halishahore under Chattogram $(\mathrm{Ctg})$ cantonment area from 16 April 2018 to 25 June 2018. Total 1304 cases of AVH got admitted and received treatment from Combined Military Hospital (CMH), Ctg during that period.
\end{abstract}

Aim: To find out the incidence, cause, predisposing factors, clinical course and to prevent such outbreaks in future.

Methods: This retrospective observational study was conducted from 16 April 2018 to 25 June 2018. Total 1304 acute viral hepatitis cases were studied for epidemiological analysis to find out the causes, mode of spread, laboratory findings and outcome.

Results: Among 1304 AVH cases $90 \%$ belonged to age group of 18-45 years and most of them were combatants and the age range was 5 to 60 years with mean age $30.31 \pm 11.29$ years. HEV was $99 \%$ etiological factor and patients' hospital stay were 10 to 55 days. Thirteen cases developed hepatic encephalopathy, 01 case developed acute pancreatitis and 108 cases had thrombocytopenia. No specific source of contamination was detected within AC\&S, although coliform bacteria were identified in drinking water supplied to the area by WASA of Ctg city.

Conclusion: We came to the conclusion that the source of infection was contaminated water supplied by WASA of Chattogram city. As we had also found that high incidence of AVH due to HEV were prevailing in Ctg city area during the same period of the outbreak.

Key-words: Acute viral hepatitis, Hepatitis E Virus, Artillery Center and School, Water and Sewerage Authority.

\section{Introduction}

Acute Viral hepatitis (AVH) is a viral infection affecting the liver predominantly. Almost all cases of AVH are caused by five viral agents; hepatitis A virus (HAV), Hepatitis B virus (HBV), Hepatitis C virus (HCV), Hepatitis D virus (HDV) and Hepatitis E virus (HEV). HEV Infection is identified in India, Asia, Africa, the
Middle East and Central America ${ }^{1}$ accounts for more than 70,000 deaths annually with approximately 20.1 million people around the world ${ }^{2}$. There is some evidence of HEV infection of animals, serving as a reservoir for human infection ${ }^{3}$. AVH outbreaks affecting tens of thousands of people in Central, South and East Asia have been documented since 1950 is thought to be due to HEV. The largest known HEV epidemic occurred from 1986-1988 in Xinjiang of China affecting over 119000 people and resulting 707 fatalities, of which 414 were pregnant women ${ }^{4}$. HEV was discovered in 1980 is essentially water borne disease. The first major epidemic was reported in New Delhi in 1955-1956 and about thirty thousand cases of jaundice were reported and retrospectively were attributed to $\mathrm{HEV}^{5}$. In most of the cases HEV outbreaks and epidemic is associated with contamination of water sources by fecal material ${ }^{6}$.

We are presenting here an acute viral hepatitis outbreak during which 1304 cases were admitted and treated in Combined Military Hospital, Chattogram. To find out the incidence, cause, predisposing factors, clinical course, outcome and to prevent such outbreaks in future this epidemiological study was planned.

\section{Material and Methods}

Armed Forces personnel in Ctg area are distributed in six large installations. Around 1,50,000 populations are dependent on health facilities of $\mathrm{CMH}$ of $\mathrm{Ctg}$, Cantonment. About 5,000 people are living in Artillery Centre and school (AC\&S) at Halishahore area under $\mathrm{Ctg}$ Cantonment. This retrospective study was carried out in $\mathrm{CMH}$, Chattogram. Necessary ethical clearances were taken from local committee. A total of 1304 patients having sign and symptoms compatible with acute viral hepatitis of both gender coming from the affected area (AC\&S) who were admitted to $\mathrm{CMH}$ Ctg from 16 April 2018 to 25 June 2018 were taken as study population. Previously diagnosed chronic hepatitis cases and cases of acute viral hepatitis admitted from other than AC\&S area were excluded. Period of reporting to hospital varied from 2 to 28 days after the onset of symptoms. Clinical information was collected from study of each case-sheet.

Informed consent was obtained from all patients during their hospital stay. Blood was tested for complete blood count (CBC), liver function test (LFT); including serum bilirubin, serum Alkaline Phosphatase (ALP), serum alanine aminotransferase

1. Col Md Ismail Chowdhury, MBBS, FCPS, MD, Classified Specialist in Medicine, CMH, Chattogram (E-mail: chowdhury.ismail@gmail.com) 2. Brig Gen Md Delwar Hossain, MBBS, FCPS, FCPS, Adviser Specialist in Medicine and Gastroenterology, CMH, Dhaka 3. Col SM Mijanur Rahman, MBBS, FCPS, FCPS, Classified Specialist in Medicine and Gastroenterology, CMH, Dhaka 4. Lt Col Mohammad Ariful Islam Miah, MBBS, FCPS, Classified Specialist in Medicine, $\mathrm{CMH}$, Chattogram. 
(ALT); complete blood count $(C B C)$, hepatitis viral profile on the 1st day of hospital admission. USG of abdomen, serum amylase, blood culture, widal test were done for appropriate cases. Blood CBC and LFT were done after every three days.

Viral Hepatitis was diagnosed on the basis of presence of typical sign symptoms, raised serum bilirubin or ALT level and positive IgM for HAV or HEV. Anicteric cases of hepatitis were diagnosed on the basis of typical symptom, more than 3-fold rise of serum ALT and having positive Anti HAV or HEV IgM. Hepatic encephalopathy was diagnosed on the basis of typical diagnostic criteria for viral hepatitis along with presence of impairment of consciousness, flapping tremor or extensor plantar reflex. Enteric fever was diagnosed on the basis of presence of moderate to high rise of body temperature for at least four days along with positive Widal test TO 1:160 or more, or positive blood culture for Salmonella or presence of positive IgM for Salmonella or typical fever respondent to antibiotic either ciprofloxacin or ceftriaxone after four days of starting treatment. Patient having platelet count less than $150 \times 10^{9} / \mathrm{L}$ were diagnosed as having thrombocytopenia.

Environment investigation: All cases came from AC\&S where about five thousand soldiers, their families and civil employee are residing. Water supply and drainage system were inspected by a survey team. Important events such as living outside garrison, leave and out pass during and after the onset of illness were considered. Underground water tanks were examined and water samples were collected from thirty different points to do the bacteriological coliform counts as an evidence of sewage contamination. Orthotolidine test was done to detect residual chlorine from water samples.

\section{Results}

The endemic was prevailing about 70 days. On an average 17 cases per day were admitted to $\mathrm{CMH}$ Chattogram from 16 April 2018 to 25 June 2018. The highest incidence of admission on 4th week of April, 117 cases on date 26 April 2018, 88 cases on 28 April 2018 and lowest incidence of admission during last week of June 2018 (average 1 cases every day). The weekly incidence of AVH during present outbreak (Table-I) and yearly incidence for last twelve years where shown in (Table-II). Among the 1304 patients studied, male was $1219(93.5 \%)$ and female was $85(6.5 \%)$. The most affected age group was between 18 to 45 years with an incidence of $90 \%$. Among them total 1157 (88.7\%) patients were suffering from isolated/only AVH and $147(21.3 \%)$ had both hepatitis and enteric fever, total 13(1.0\%) patients developed hepatic Encephalopathy (Figure-2). Signs/ symptoms analysis reveals yellow colouration of urine (88.5\%), jaundice (87.0\%), anorexia (98.6\%), malaise (94.0\%) and fever (52.0\%) (Table-III). Serum bilirubin was found normal (0.8 to 1.2) in 169 cases, mild elevation of bilirubin (1.3-3.0 mg/dl) having $336(26.0 \%)$ cases, moderate to marked elevation (serum bilirubin > $3.0 \mathrm{mg} / \mathrm{dl}$ ) were 799 (61.3\%) cases. ALT level
1500-2000 IU/L found in $30.6 \%$ cases, $>2500$ IU/L found $23.6 \%$ cases (Table-IV). Total 108 (8.3\%) cases were having various level of thrombocytopenia $\left(140\right.$ to $\left.30 \times 10^{9} / /\right)$ and improved without causing any clinical deterioration (Figure-1). Single case developed clinically and biochemically acute pancreatitis. Anti HEV IgM positive cases were 1291(among 1304) that is $99.0 \%$ and 13 cases (1.0\%) were anti HAV IgM positive (Figure-3). Duration of stay in hospital also varied among them. The average duration of admission was 22 days, shortest 10 days and the longest 55 days. The patients were discharged after significant clinical and biochemical improvement. They were advised for LFT after four weeks of discharge. All cases were followed up and found to have normal LFT after four weeks of discharge.

Table-I: Weekly Incidence of AVH: 16 April to 25 June 2018 $(n=1304)$

\begin{tabular}{|l|c|c|}
\hline \multicolumn{1}{|c|}{ Week } & Frequency & $\%$ \\
\hline 16 Apr to 22 Apr 2018 & 143 & 11.0 \\
\hline 23 Apr to 29 Apr 2018 & 442 & 34.0 \\
\hline 30 Apr to 6 May 2018 & 238 & 18.3 \\
\hline 7 May to 13 Ma y 2018 & 209 & 16.0 \\
\hline 14 May to 20 May 2018 & 137 & 10.5 \\
\hline 21 May to 27 May 2018 & 87 & 6.7 \\
\hline 28 May to 3 Jun 2018 & 32 & 2.5 \\
\hline 4 Jun to 10 Jun 2018 & 8 & 0.6 \\
\hline 11 Jun to 17 Jun 2018 & 4 & 0.3 \\
\hline 18 Jun to 25 Jun 2018 & 4 & 0.3 \\
\hline
\end{tabular}

Table-II: Yearly incidence of AVH in Chattogram area admitted at $\mathrm{CMH}$ Chattogram

\begin{tabular}{|c|c|}
\hline Year & Acute viral hepatitis(AVH) cases \\
\hline 2007 & 123 \\
\hline 2008 & 130 \\
\hline 2009 & 181 \\
\hline 2010 & 107 \\
\hline 2011 & 57 \\
\hline 2012 & 698 \\
\hline 2013 & 76 \\
\hline 2014 & 51 \\
\hline 2015 & 29 \\
\hline 2016 & 42 \\
\hline 2017 & 36 \\
\hline 2018 & 1304 \\
\hline
\end{tabular}

Note: Data source CMH Chattogram records

Table-III: Distribution of patients by predominant signs \& symptoms $(n=1304)$

\begin{tabular}{|l|c|c|}
\hline Signs \& symptoms & Frequency & $\%$ \\
\hline Anorexia & 1285 & 98.6 \\
\hline Malaise & 1225 & 94.0 \\
\hline Yellow Urine & 1154 & 88.5 \\
\hline Icteric & 1135 & 87.0 \\
\hline Fever & 678 & 52.0 \\
\hline Vomiting & 673 & 51.6 \\
\hline Anicteric & 169 & 13.0 \\
\hline
\end{tabular}


Table-IV: Distribution of patients by laboratory findings $(n=1304)$

\begin{tabular}{|l|l|c|r|}
\hline \multicolumn{2}{|c|}{ Laboratory investigation } & Frequency & $\%$ \\
\hline \multirow{3}{*}{$\begin{array}{l}\text { Bilirubin } \\
\text { (mg/dl) }\end{array}$} & $0.8-1.2$ & 169 & 13.0 \\
\cline { 2 - 4 } & $1.3-3.0$ & 336 & 26.0 \\
\cline { 2 - 4 } & $3.1-70$ & 799 & 61.3 \\
\hline \multirow{5}{*}{ ALT (IU/L) } & $150-250$ & 127 & 9.7 \\
\cline { 2 - 4 } & $251-500$ & 109 & 8.4 \\
\cline { 2 - 4 } & $501-1000$ & 99 & 7.6 \\
\cline { 2 - 4 } & $1001-1500$ & 135 & 10.4 \\
\cline { 2 - 4 } & $1501-2000$ & 399 & 30.6 \\
\cline { 2 - 4 } & $2001-2500$ & 127 & 9.7 \\
\cline { 2 - 4 } & $>2500$ & 308 & 23.6 \\
\hline
\end{tabular}

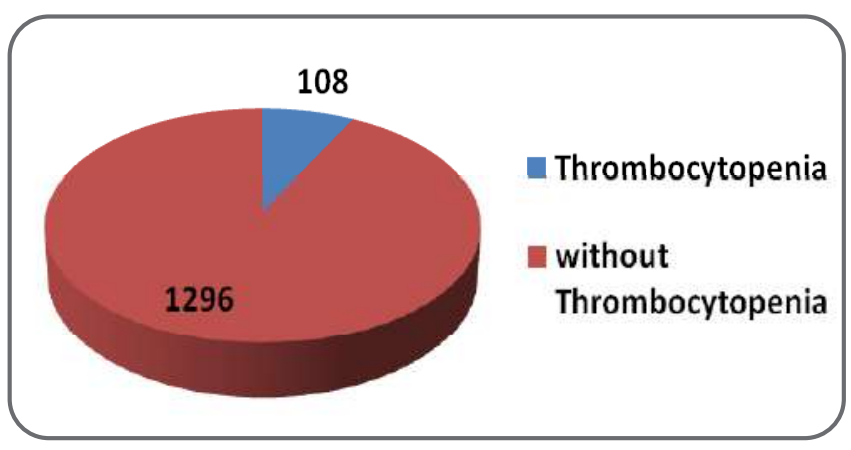

Figure-1: $A V H$ with Thrombocytopenia and without Thrombocytopenia

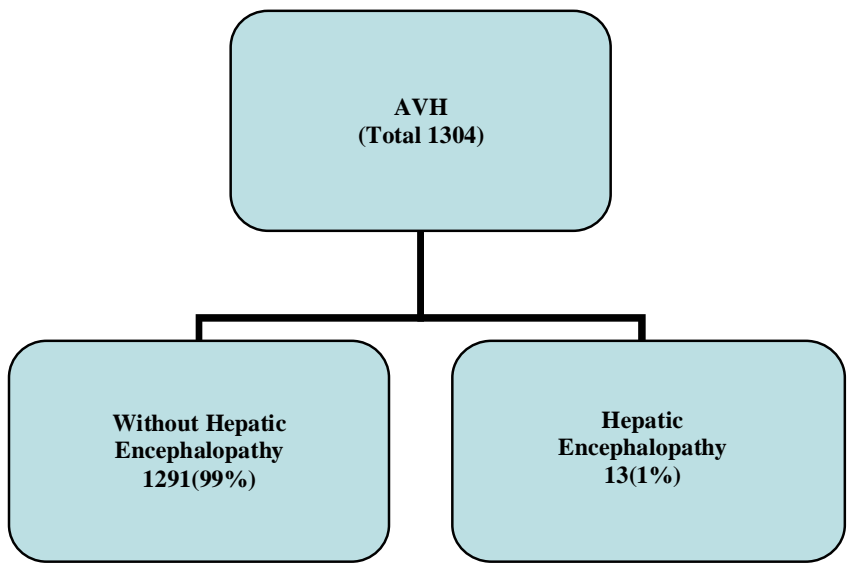

Figure-2: Number and percentage of Hepatic Encephalopathy $(n=1304)$

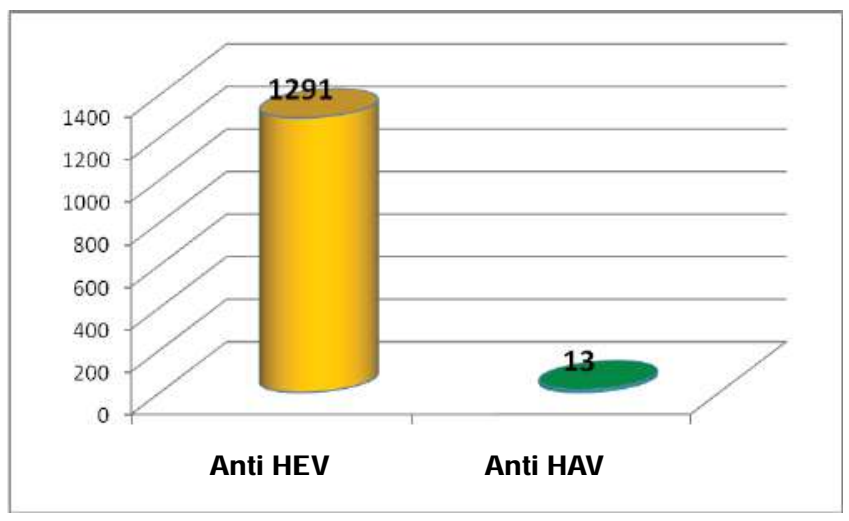

Figure-3: Anti HEV IgM \& Anti HAV IgM positive cases

\section{Discussion}

Outbreaks of acute hepatitis in an area are intimately related to contaminated water, as a source of infection. HEV exposure is influenced by environmental and living condition. Frequent low dose exposure to HEV bestows immunity to people living in unhygienic conditions ${ }^{7}$. This study populations are relatively non immune to HEV due to living in an improved environmental condition and better sanitary infrastructure. This study is clearly indicating an endemic outbreak. It is obvious from the previous record that the incidence of $\mathrm{AVH}$ markedly increased in the year of 2018 compared that of previous five years. The total numbers of AVH were 1304 clearly outnumbered the total case (234) from 2013 to 2017. Another outbreaks of HEV infection occurred (698 cases) in 2012 at Chattogram Cantonment area. Many HEV epidemics have been reported throughout the world. In 2015, an outbreak of HEV was reported in the district of Shimla, Himachal Pradesh, India. They reported 264 cases were reported to have suffered from acute HEV ${ }^{8}$. By extensive bio-chemical and serological analysis, the epidemic of hepatitis is now-a-days can be diagnosed with high sensitivity and specificity. Analysis of viral markers in this study revealed isolated viral infection in 1157 (88.7\%) cases; co infection with enteric fever were detected in 147 (21.3\%) patients. The majority (99\%) of infection was due to findings is almost similar to the study conducted in department of medicine Army Medical College and Military Hospital Rawalpindi Pakistan in 2009 where HEV constituted $90 \%$ of the study population ${ }^{9}$.

Bryan et al who studied hepatitis E epidemics in Abottabad, found $50 \%$ of total AVH cases admitted to their Military hospital were due to HEV which showed significant difference from our study ${ }^{10}$. The age distribution of cases in this study was 5 to 60 years with mean age $30.3 \pm 11.3$ years which is similar to that described by Sarquna et $\mathrm{al}^{11}$. In the study outbreak of acute viral hepatitis due to hepatitis $E$ in Hyderabad. Adults in the age group of 18 to 45 years (90\%) were being predominantly affected in this study (as study populations were mil soldiers and few family members). Children $<10$ years were spared, as has been also observed in earlier epidemics of Non-A, Non-B hepatitis ${ }^{12,13}$. Women and children in the cantonment relatively spared possibly due to the habit of drinking boiling water in the family accommodation. Also could be because of anicteric hepatitis or sub-clinical infection is common in children under 10 years of age in endemic hepatitis ${ }^{14}$. An alternative explanation could be that HEV is maintained in the community as a sporadic infection; thus HEV is acquired early in life, making infants and children immune to another attack ${ }^{15-17}$. The clinical features of HEV are nearly specific. This study showed the clinical features of yellow coloration of urine (88.5\%), jaundice $(87.0 \%)$, anorexia (98.6\%), malaise (94.0\%), vomiting (51.6\%) and fever $(52.0 \%)$ which is almost similar to Worm et $a^{18}{ }^{18}$, where jaundice, malaise and anorexia are reported by almost 100\% patient. In this study, we found 13 cases of acute hepatic encephalopathy. Mild elevation of serum bilirubin found in 336 cases (26.0\%), moderate to marked elevation 799 cases (61.3\%), with normal bilirubin in 169 (13.0\%)-(anicteric hepatitis). 
A high level of ALT is an important parameter in the course of liver disease. This confirms the presence of hepatic cell injury which usually accompanies infection with hepatitis viruses ${ }^{19}$. In this study, ALT were found to be $>5$ times in 1176 cases $(90.2 \%)$. HEV infection initiates immuno allergic mechanism which may cause thrombocytopenia and in the present study, we found 108 cases had low platelet level of different ranges below $150 \times 10 \% / \mathrm{L}$. In this study there is no fatality even those who presented with pregnancy and who developed hepatic encephalopathy. It has been shown in one study that $23 \%$ of pregnant women had fatal outcome (all in the third trimester) ${ }^{20,}{ }^{21}$ due to isolated HEV infection . Pregnant women are at higher risk in development of fulminant hepatic failure, fatality rate increases with the length of the pregnancy period ${ }^{22}$. This study cannot be compared as there was no mortality but we treated 2 pregnant women with HEV infection in their $2 \mathrm{nd} / 3 \mathrm{rd}$ trimester. Pregnant women with jaundice are 5 times more likely to die than non-pregnant women with Jaundice $^{23}$. The average hospital stays of our patients were 22 days; the highest was 55 days and the minimum was 10 days. Waqar Azim et $\mathrm{al}^{24}$ in their study showed average hospital stay was 17 days and the longest was 37 days.

Prevention: Drinking safe water and improving sanitation is the utmost important factors in preventing HEV infection. Special attention should be given to a crowded area where a large number of people uses common source of water and sanitation. Proper disposal of human waste, improving personal hygiene and ensuring safe water supply are most important. This requires educating people regarding safe water and hygiene, regular monitoring of water sources and adequate financing in water supply and water treatment projects. HEV vaccine recently is available and should be given to high risk population (military personnel of a developing country). The vaccine appeared to be effective and safe ${ }^{25}$.

\section{Conclusion}

This study found no specific symptoms or signs which can detect HEV clinically. The clinical signs and symptoms dominated by jaundice, vomiting, anorexia and malaise are not specific to HEV infection but can orient the clinician in the event of a hepatitis outbreak. In order to avoid repetitive outbreak of HEV in an army institution, it would be desirable to reinforce the preventive measures of individual and collective hygiene and set up a monitoring system.

\section{References}

1. Diestag JL. Acute viral hepatitis, In: Jameson, Fauci, Kasper, Hauser, Longo, Loscalzo, Harrison's Principles of internal medicine, 20th ed. McGraw-Hill; 2018:2347

2. Kumar S, Panda BK. Hepatitis E virus: The current scenario. International Journal of Infectious Disease 2013; 17:228-33.

3. Carrol KC, Morse SA, Mietzner T, Miller S. Medical Microbiology, 27th ed. McGraw Hill, 2015:499
4. Teo CG. Fatal outbreak of Jaundice in pregnant and the epidemic history of Hepatitis E. Epidemiol Infect 2012; 140:767-87.

5. Krawezynski K. Hepatitis E. Hepatol 1992; 17:932-41.

6. Jules L. Diestag, Acute viral hepatitis, In: Kasper, Fauci, Hauser, Longo, Jameson, Loscalzo, Harrison's Principles of internal medicine, 19th ed. MeGraw Hill, 2015.

7. Christensen $\mathrm{PB}$, Engle RF, Hijort $\mathrm{C}$ et al. Time trend of the prevalence of hepatitis $\mathrm{E}$ Antibodies among farmers and blood donors: A potential zoonosis in Denmark. Clinical Infectious Disease 2008; 47:1026-31.

8. Ganju SA, Goutom N. Seroepidemiology of a recent outbreak of Hepatitis $E$ in urban Shimla, Himachol Pradesh, India. Journal of Communicable Diseases 2017; 49(2):17-8.

9. Waqar A, Wajiha F, Saad A et al. Clinical presentation in an outbreak of hepatitis E. J Biomedica 2010; 26:58-60.

10. Bryan JP, IpbaL M, Tsarev S et al. Epidemic of hepatitis $E$ in a military unit in Abbottabad, Pakistan. Am J Trop Med Hyg 2002; 67(6):662-8.

11. Sarquna P, Rao A, Ramana KNS. Outbreak of acute viral hepatitis $E$ virus in Hyderabad. Indian Journal of Medical Microbiology 2007; 25(4):378-82.

12. Tandon BN, Joshi YK, Jain SK et al. An epidemic of non-A, non-B hepatitis in North. Indian J Med Res 1982; 75:739-44.

13. Dilawari JB, Singh K, Chawla YK et al. Hepatitis $E$ virus: Epidemiological, clinical and serological studies of north Indian epidemic. Indian J Gastroenterol 1994; 13:44-8.

14. Uchida T. Hepatitis E virus. Gastroenterol Jpn 1992; 27:667-96.

15. Chuhan AC, Dilwari JB, Jameel $S$ et al. Common aetiological agent for epidemic and sporadic Non-A, Non-B hepatitis. Lancet 1992; 339:1509-10.

16. Balayan MS. New form of hepatitis with feco-oral mode of spread. Soc Med Rev E Virol 1987; 2:235-61.

17. Datta R, Panda SK, Tandon BN et al. Acute sporadic Non-A, Non-B viral hepatitis of adult in India: Epidemiological and immunological studies. J Gastroenterol Hepatol 1987; 2:35- 45.

18. Worm HC, Poel WHM, Brandstatter G. Hepatitis E and overview. Microbes and infection 2002; 4:657-66.

19. Panda SK, ThakraL D, Rehman S. Hepatitis $E$ virus. Reviews in Medical Virology 2007; 17:151-80.

20. Khuroo MS, Saleem M, Teli MR et al. Incidence and severity of viral hepatitis in pregnancy. Am J Med 1981; 70:252-5.

21. Dilawari JB, Singh K, Chawla YK et al. Hepatitis E virus: Epidemiological, clinical and serological studies of north Indian epidemic. Indian J Gastroenterol 1984; 13:44-8.

22. Terrault NA, Wright TL. Viral hepatitis A through G, In: Sleisenger and Fordtran's Gastrointestinal and Liver disease, 6th ed. WB Saunders Company 1998:1123-70. 
23. Outbreak of hepatitis $E$ in low income urban community in Bangladesh. ICDDRB. Health and Science Bulletin, Sep 2009; 7:3.

24. Waqar A, Wajiha F, Saad A et al. Clinical presentation in an outbreak of hepatitis E. J Biomedica Jan-Jun 2010; 26: 58-60.
25. Shrestha MP, Scott RM, Joshi DM et al. Safety and efficacy of a recombinant hepatitis $E$ vaccine. The New England journal of medicine 2007; 356(9):895-903. 